\title{
HUBUNGAN ANTARA TINGKAT PENGETAHUAN IBU DENGAN STATUS GIZI BALITA DI KELURAHAN WONOREJO KABUPATEN KARANGANYAR
}

\section{The Correlation Between Mother's Knowledge with Nutritional Status of Toddlers in Wonorejo Village Karanganyar Regency}

\author{
Agus Eka Nurma Yuneta ${ }^{1)}$, Hardiningsih ${ }^{2)}$, Fresthy Astrika Yunita ${ }^{3)}$ \\ *)Jurusan Kebidanan, Fakultas Kedokteran, Universitas Sebelas Maret \\ Jl. Ir Sutami 36A, Kentingan Surakarta 57126 Telp (0271) 662622
}

E-mail:ekayuneta@yahoo.com

\begin{abstract}
ABSTRAK
Latar belakang: Angka kematian balita (AKBA) merupakan indikator utama derajat kesehatan masyarakat. Balita yang mengalami gizi kurang pada dua tahun pertama kehidupannya, akan terjadi keterlambatan pertumbuhan fisik dan mental. Berdasarkan data dinas kesehatan tahun 2015 triwulan ketiga di Jawa Tengah angka kematian balita sebanyak 4.258 kasus, tahun 2014 sebanyak 6.486 kasus (11,54 per1.000 Kelahiran hidup). Persentase balita dengan gizi kurang ada $2,73 \%$, gizi buruk ada $0,38 \%$. Tujuan penelitian adalah menganalisis hubungan antara tingkat pengetahuan ibu dan status gizi balita di Kelurahan Wonorejo Karanganyar.

Subjek dan Metode: Desain penelitian adalah cross sectional. Penelitian dilakukan di posyandu kelurahan Wonorejo Kabupaten Karanganyar. Populasi penelitian ini adalah ibu yang mempunyai balita usia 1-5 tahun dan semua balita di posyandu kelurahan Wonorejo. Teknik pencuplikan sampel menggunakan cluster random sampling. Alat ukur dalam penelitian ini adalah kuesioner untuk mengukur tingkat pengetahuan ibu, untuk mengukur status gizi balita dengan mengukur berat badan menggunakan dacin atau timbangan injak.

Hasil: Hasil analisis data menggunakan Kendall's tau didapatkan nilai $p$ sebesar 0,000 ( $\mathrm{p}<$ $0,05)$ yang menyatakan terdapat korelasi yang bermakna dan nilai korelasi pada penelitian ini adalah sebesar 0,482 yang menyatakan kekuatan korelasi sedang dengan arah yang positif.

Kesimpulan: Terdapat hubungan yang signifikan antara tingkat pengetahuan ibu dan status gizi balita di Kelurahan Wonorejo.
\end{abstract}

Kata kunci: Tingkat pengetahuan, status gizi, balita. 


\section{ABSTRACT}

Background: Mortality toddlers (AKBA) is a leading indicator of public health. Toddlers who experience malnutrition in the first two years of life, there will be a delay in physical and mental growth. Based on data from 2015 third quarter health office in Central Java the under-five mortality rate was 4,258 cases, in 2014 there were 6,486 cases (11.54 per 1,000 live births). The percentage of infants with malnutrition was $2.73 \%$, malnutrition was $0.38 \%$. The purpose of the study was to analyze the relationship between the level of maternal knowledge and nutritional status of children in Wonorejo Karanganyar Village.

Subject and Method: The study design was cross sectional. The study was conducted at the posyandu in the village of Wonorejo, Karanganyar Regency. The population of this study is mothers who have toddlers aged 1-5 years and all toddlers at the posyandu in the village of Wonorejo. Sampling techniques using cluster random sampling. The measurement tool in this study was a questionnaire to measure the level of knowledge of mothers, to measure the nutritional status of toddlers by measuring body weight using dacin or injak scales.

Results: Data analysis using Kendall's tau found p value 0,000 ( $p<0,05)$ represent that there is correlation and the correlation value is 0,482 represent medium correlation with positive direction.

Conclusion: There is significant correlation between mother's knowledge with nutritional status of toddlers in Wonorejo Village Karanganyar Regency.

Keywords: Knowledge level, nutritional status, toddler

\begin{tabular}{l}
\hline PENDAHULUAN \\
\hline Angka kematian balita (AKBA) merupa- \\
kan indikator utama derajat kesehatan ma- \\
syarakat. Lebih dari sepertiga dari semua \\
kematian balita setiap tahun di seluruh du- \\
nia dikaitkan dengan gizi kurang. Daya ta- \\
han tubuh dan sistem pencernaan balita \\
masih imatur menyebabkan balita lebih \\
berisiko terserang penyakit dibanding \\
orang dewasa ${ }^{[4]}$. Balita yang mengalami \\
gizi kurang pada dua tahun pertama kehi- \\
dupannya, akan terjadi keterlambatan per- \\
tumbuhan fisik dan mental. Masalah ini \\
tidak dapat diperbaiki dengan bertambah- \\
nya usia anak dan hal ini akan mempenga- \\
ruhi anak seumur hidupnya ${ }^{[1]}$. Oleh sebab \\
itu, perbaikan gizi masyarakat yang difo- \\
kuskan pada perbaikan gizi bayi dan anak \\
balita merupakan awal dalam meningkat- \\
kan derajat kesehatan masyarakat. Sebalik- \\
nya kekurangan gizi pada balita akan ber- \\
akibat terhadap munculnya masalah kese- \\
hatan yang lain, dan akhirnya akan ber- \\
dampak terhadap menurunnya derajat ke- \\
sehatan masyarakat ${ }^{[5]}$. \\
Salah satu faktor penting yang mem- \\
pengaruhi status gizi pada balita adalah
\end{tabular}

faktor pengetahuan ibu tentang gizi pada balita. Kurangnya pengetahuan ibu tentang keragaman bahan dan keragaman jenis makanan akan menimbulkan terganggunya proses pertumbuhan dan perkembangan balita terutama perkembangan otak, oleh karena itu penting untuk ibu dalam memberikan asupan makanan yang bergizi kepada anaknya. Banyak orang tua terutama ibu yang tidak memperhatikan asupan nutrisi pada anak balitanya. Padahal anak usia balita rentan terhadap penyakit dan infeksi ${ }^{[2]}$.

Berdasarkan data dari dinas kesehatan tahun 2015 pada triwulan ketiga di Jawa Tengah angka kematian balita terlaporkan sebanyak 4.258 kasus sedangkan pada tahun 2014 angka kematian balita ada sebanyak 6.486 kasus $(11,54$ per 1.000 Kelahiran hidup $)^{[6]}$. Hal ini terjadi penurunan dibandingkan pada tahun 2013 yaitu sebesar 11,80 per 1.000 Kelahiran hidup. Akan tetapi permasalahan gizi yang masih tetap ada yaitu tentang masalah gizi kurang dan gizi buruk. Persentase balita dengan gizi kurang ada $2,73 \%$, gizi buruk ada $0,38 \%{ }^{[3]}$. 
Karanganyar merupakan salah satu kabupaten yang mempunyai jumlah penduduk sebanyak 861.845 jiwa yang terletak disebelah timur dari kota Surakarta. Peranan wanita atau ibu rumah tangga merupakan penentu dalam usaha perbaikan gizi keluarga. Tingkat pendidikan ibu yang baik akan memberikan pemahaman yang baik pula pada ibu untuk meningkatkan status gizi balita ${ }^{[7]}$.

Kasus gizi pada balita di Kabupaten Karanganyar sendiri dari tahun ke tahun mengalami perubahan yang fluktuatif. Tahun 2013 persentase kejadian gizi kurang $2,69 \%$, dan gizi buruk $0,31 \%$. Kemudian di tahun 2014 persentase bayi dua tahun dengan berat badan dibawah garis merah sebesar $0,45 \%$ dan balita dengan berat badan dibawah garis merah sebesar $0,83 \%{ }^{[8]}$. Senada dengan data ini, Departemen kesehatan kabupaten Karanganyar mengatakan Pada tahun 2014 di Kabupaten Karanganyar terdapat $6,8 \%$ balita kekurangan gizi.

Tujuan umum penelitian ini adalah mengetahui hubungan antara tingkat pengetahuan ibu dengan status gizi balita di Kelurahan Wonorejo. Tujuan khusus dari penelitian ini adalah untuk mengetahui bagaimana tingkat pengetahuan ibu tentang gizi balita di Kelurahan Wonorejo, status gizi balita di Kelurahan Wonorejo dan hubungan antara tingkat pengetahuan ibu dengan status gizi balita di Kelurahan Wonorejo.

Hasil penelitian dapat digunakan sebagai masukan bagi Dinas Kesehatan Kabupaten Karanganyar dalam upaya peningkatan status gizi balita di Kelurahan Wonorejo dan sebagai dasar dalam melakukan tindak lanjut berupa pemberdayan ibu agar status gizi balita dapat menjadi baik .

\section{SUBJEK DAN METODE}

Jenis penelitian observasional analitik dengan desain penelitian cross sectional. Penelitian ini dilakukan di posyandu Kelurahan Wonorejo Kabupaten Karanganyar. Populasi pada penelitian ini adalah ibu yang mempunyai balita (usia 1-5 tahun) beserta bayinya di posyandu Kelurahan Wonorejo Kabupaten Karanganyar yang berjumlah 50 orang. Teknik pengambilan sampel pada penelitian ini yaitu dengan cluster random sampling.

\section{HASIL}

1. Deskripsi Data

Penelitian ini dilaksanakan di 18 Posyandu Kelurahan Wonorejo Kabupaten Karanganyar pada bulan Juni sampai dengan November 2018, Populasi penelitian yaitu semua balita di Posyandu Kelurahan Wonorejo Kabupaten Karanganyar serta ibu yang mempunyai anak balita usia 1-5 tahun di Posyandu Kelurahan Wonorejo. Teknik sampel yang digunakan adalah cluster random sampling.

2. Pengetahuan

Analisis data dilakukan secara komputerisasi menggunakan program SPSS 20.0 dengan uji statistik Kendall's tau dengan hasil sebagai berikut:

Dalam penelitian ini pengetahuan reponden yaitu ibu bayi balita setelah penyebaran kuesioner pada saat penelitian hasil yang didapat disajikan dalam tabel berikut:

Tabel 1. Distribusi Frekuensi Responden Berdasarkan Pengetahuan Ibu di Kelurahan Wonorejo Kabupaten Karanganyar.

\begin{tabular}{ccc}
\hline Pengetahuan & Frekuensi & $\begin{array}{c}\text { Persentase } \\
(\%)\end{array}$ \\
\hline Tinggi & 11 & 22,00 \\
Sedang & 33 & 66,00 \\
Rendah & 3 & 12,00 \\
Total & 50 & 100,00 \\
\hline
\end{tabular}

Berdasarkan tabel di atas dapat diketahui bahwa sebagian besar responden berpengetahuan tinggi sebanyak 11 orang (22\%), Sedang sebanyak 33 orang $(66 \%)$, dan rendah sebanyak 3 orang $(12 \%)$. Dapat disimpulkan pengetahuan yang paling banyak adalah sebanyak 33 orang $(66 \%)$. 
3. Usia

Usia Responden Penelitian ini setelah penyebaran kuesioner pada saat penelitian hasil yang didapat disajikan dalam tabel berikut:

Tabel 2. Distribusi Frekuensi Usia Responden

\begin{tabular}{ccc}
\hline Usia & Frekuensi & Persentase \\
\hline $20-35$ th & 49 & 98,00 \\
$>35$ th & 1 & 2,00 \\
Total & 50 & 100,00 \\
\hline
\end{tabular}

Berdasarkan tabel di atas dapat diketahui bahwa sebagian besar responden memiliki Usia antara 20-30 th sebanyak 49 orang $(98 \%),>35$ th sebanyak 1 orang (2\%). Dapat disimpulkan Usia yang paling banyak adalah antara 20-30 th sebanyak 49 orang (98\%).

4. Pendidikan

Pendidikan Responden Penelitian ini setelah penyebaran kuesioner pada saat penelitian hasil yang didapat disajikan dalam tabel berikut:

Tabel 3. Distribusi Frekuensi Responden Berdasarkan Pendidikan Ibu di Kelurahan Wonorejo Kabupaten Karanganyar

\begin{tabular}{ccc}
\hline Pendidikan & Frekuensi & $\begin{array}{c}\text { Persentase } \\
(\%)\end{array}$ \\
\hline SD & 4 & 8,00 \\
SMP & 12 & 24,00 \\
SMA & 27 & 54,00 \\
PT & 7 & 14,00 \\
Total & 50 & 100,00 \\
\hline
\end{tabular}

Berdasarkan tabel di atas dapat diketahui bahwa sebagian besar responden Berpendidikan SMA sebanyak 27 orang (54\%), Berpendidikan SMP sebanyak 12 orang $(24 \%)$, berpendidikan SD 4 orang $(8 \%)$ dan Berpendidikan Perguruan Tinggi sebanyak 7 orang (14\%) Dapat disimpulkan pendidikan terbanyak adalah SMA sebanyak 27 orang (54\%).

5. Status Gizi

Status Gizi Balita pada penelitian ini setelah dilakukan penimbangan pada saat penelitian hasil yang didapat disajikan dalam tabel berikut:

Tabel 4. Distribusi Frekuensi Responden Berdasarkan Status Gizi di Kelurahan Wonorejo Kabupaten Karanganyar

\begin{tabular}{cc}
\hline Status Gizi & Frekuensi \\
\hline Gizi Baik & 45 \\
Gizi Kurang & 5 \\
Total & 50 \\
\hline
\end{tabular}

Berdasarkan tabel di atas dapat diketahui bahwa sebagian besar Status Gizi bayi balita di wonorejo Gizi Baik sebanyak 45 anak (90\%) dan Satatus Gizi Kurang Sebanyak 5 anak (10\%), Sehingga secara keseluruhan Sataus Gizi di wonorejo sebanyak $90 \%$ baik,

6. Hubungan Tingkat Pengetahuan dengan Status Gizi

Hubungan tingkat pengetahuan ibu dengan status gizi setelah dilakukan analisis dengan Kendall's Tau didapatkan hasil nilai $\mathrm{p}=0,000$ yang berarti nilai $p<0,01$ sehingga dapat dikatakan ada hubungan antara tingkat pengetahuan ibu dengan status gizi balita di Kelurahan Wonorejo Kabupaten Karanganyar.

\section{PEMBAHASAN}

Penelitian ini ingin mengetahui hubungan antara tingkat pengetahuan ibu dengan status gizi balita di Kelurahan Wonorejo Kabupaten Karanganyar. Berdasarkan data yang terkumpul dan dianalisis kemudian dilakukan pembahasan mengenai hasil penelitian sebagai berikut:

Hasil penelitian dari 50 responden ibu yang berada di Wonorejo Karanganyar didapatkan tingkat pengetahuan berpengetahuan baik responden berpengetahuan tinggi sebanyak 11 orang (22\%), Sedang sebanyak 33 orang (66\%), dan rendah sebanyak 3 orang (12\%). Dapat disimpulkan pengetahuan yang paling banyak adalah sebanyak 33 orang (66\%).

Pengetahuan adalah hasil dari tahu dan ini terjadi setelah orang melakukan 
penginderaan terhadap suatu objek tertentu. Penginderaan terjadi melalui panca indra manusia, yaitu: penglihatan, pendengaran, penciuman, rasa dan raba ${ }^{[9] .}$

Menurut penelitian Wahyuni 2015 dalam judulnya Hubungan Karakteristik Keluarga dengan Kejadian Stunting Pada Anak Usia 2-5 Tahun, Tingkat pengetahuan bisa dipengaruhi oleh beberapa faktor yaitu umur, intelegensi, lingkungan, sosial budaya, pendidikan, informasi, dan pengalaman $^{[10]}$.

Pengetahuan erat kaitannya dengan pendidikan, dimana dapat diasumsikan bahwa seseorang dengan pendidikan tinggi akan semakin luas pula pengetahuannya. Tingkat pengetahuan ibu menjadi kunci dalam pengelolaan rumah tangga, hal ini akan mempengaruhi sikap ibu dalam pemilihan bahan makanan yang nantinya akan dikonsumsi oleh keluarga. Ibu dengan pengetahuan gizi yang baik akan mengerti dan memahami pentingnya status gizi yang baik bagi kesehatan serta kesejahteraan. Sejalan juga dengan penelitian Nugrahani dkk dengan judul Perbedaan Kejadian Gizi Lebih pada Balita Usia 1-2 tahun dengan Riwayat Pemberian Asi Eksklusif yang menyatakan, Tingkat pendidikan berhubungan dengan pengetahuan seseorang. Tingkat pendidikan turut menentukan mudah tidaknya seseorang menyerap dan memahami pengetahuan gizi yang mereka peroleh.

\section{SIMPULAN DAN SARAN}

\section{Simpulan}

Hasil analisis dan pembahasan hubungan tingkat pengetahuan dan status gizi balita yang telah diuraikan pada bab sebelumnya, sehingga dapat ditarik kesimpulan sebagai berikut:

1. Pengetahuan responden tentang status gizi balita 66 responden (66\%) terdistribusi dalam kategori sedang.

2. Status gizi balita dalam kategori status gizi baik (normal) sebanyak 90 responden $(45 \%)$.
3. Hasil analisis data menggunakan Kendall's tau didapatkan nilai $p$ sebesar $0,000(\mathrm{p}<0,05)$ yang menyatakan terdapat korelasi yang bermakna dan nilai korelasi pada penelitian ini adalah sebesar 0,482 yang menyatakan kekuatan korelasi sedang dengan arah yang positif. Sehingga hipotesis penelitian menyatakan bahwa terdapat hubungan yang signifikan antara tingkat pengetahuan ibu dan status gizi balita di Kelurahan Wonorejo.

\section{Saran}

1. Bagi Orang Tua Balita di Kelurahan Wonorejo

Orang tua sebaiknya lebih aktif dalam mencari pengetahuan tentang pemberian gizi pada balita melalui cara dengan aktif mengikuti posyandu, bertanya ke tenaga kesehatan atau mencari informasi dari media massa agar tumbuh kembang balita sesuai.

2. Petugas Kesehatan dan Kader Posyandu

Petugas kesehatan dan kader posyandu agar lebih berupaya untuk meningkatkan kegiatan penyuluhan yang dapat meningkatkan pengetahuan ibu tentang pentingnya pemberian giziyang baik pada balitanya.

\section{UCAPAN TERIMAKASIH}

Laporan akhir kegiatan penelitian ini dapat terselesaikan berkat adanya bantuan dari berbagai pihak. Melalui kesempatan ini penulis sampaikan ucapan terima kasih yang sebesar-besarnya kepada :

1. Bapak Rektor dan Ketua Lembaga Penelitian dan Pengabdian Pada Masyarakat serta Dekan Fakultas Kedokteran Universitas Sebelas Maret Surakarta yang telah memberikan persetujuan penelitian.

2. Kepala Dinas Kesehatan Kab. Karanganyar dan Kepala Kecamatan Gondangrejo yang telah memberikan izin penelitian 
3. Kepala Kelurahan Wonorejo beserta seluruh stafnya, yang telah memberikan izin, dukungan dan fasilitasi dalam pelaksanaan penelitian

4. Bidan di PKD Wonorejo yang telah memberikan izin dan bantuan dalam pelaksanaan penelitian

5. Kader kesehatan di wilayah kerja PKD Wonorejo yang telah membantu dalam pelaksanaan penelitian

6. Ibu-ibu yang memiliki balita di wilayah Kelurahan Wonorejo yang telah bersedia menjadi responde dalam penelitian ini

7. Semua pihak yang telah membantu dalam pelaksanaan penelitian

\section{DAFTAR PUSTAKA}

1. UNICEF. 2010. Fact for Life. June 24 , 2016. http://www.unicef.org/publication/f iles/FactforLiteEN010810.pdf

2. Istiyani.2013. Pola Asuh pada Balita Gizi Baik dan Gizi Buruk. Naskah Publikasi. Fakultas Ilmu Kesehatan. Universitas Muhammadiyah Surakarta, pp: 132-139.

3. Dinas Kesehatan Provisi Jawa Tengah. 2014. Profil Kesehatan Jateng Tahun 2014. Semarang : Dinkes Jateng.

4. Rahmah, Q., Rezkina, E., dan Agustin, A. 2015. Buku Ajar Gizi dalam Daur Kehidupan. Jakarta: EGC, pp: 78-96.

5. Notoatmodjo, S .2012. Ilmu Perilaku Kesehatan.Jakarta: Rineka Cipta, pp: 26-29

6. Dinas Kesehatan Kabupaten Karanganyar.2015. Profil Kesehatan Kabupaten Karanganyar Tahun 2015. Karanganyar: Dinkes Karanganyar, pp: 12-13.

7. Sirait, A. 2011.Faktor-Faktor yang Berhubungan dengan Status Gizi Balita di Kabupaten Deli Serdang 2011, pp: 177-188.

8. Dinas Kesehatan Kabupaten Karanganyar. 2014. Profil Kesehatan Kabupaten Karanganyar Tahun 2014. Karanganyar: Dinkes Karanganyar, pp: 25-27.

9. Notoatmodjo, S. 2010. Metode Penelitian Kesehatan. Edisi Revisi. Jakarta: Rineka Cipta, pp: 75-115.

10. Wahyani. 2015. Hubungan antara Tingkat Pengetahuan Ibu tentang Gizi dengan Status Gizi Balita di Kelurahan Pleret, Bantul. Skripsi. Naskah Publikasi. Sekolah Tinggi Ilmu Kesehatan. 'Aisyiyah Yogyakarta, pp: 49-52. 